\title{
An Empirical Study of English Reading Strategies for Mechanical and Electrical Majors in the Vocational College
}

\author{
Ronggen Zhang ${ }^{1, a}$ \\ Shanghai Publishing and Printing College ,Shanghai, China
}

zrgen@163.com

\begin{abstract}
Keywords: Empirical Study, English reading strategies, Mechanical and electrical majors, Vocational college
\end{abstract}

\begin{abstract}
By making questionnaires of the freshmen of a vocational college in Shanghai, the paper makes an empirical study of English reading strategies for vocational college students. The findings include that the students generally use the reading strategies not so often, among the three strategies, the meta-cognitive strategies use most frequent, and the social-affective strategies use less frequent; that the female students use the three categories of reading strategies more frequently than their counterpart males; and that those less frequently using cognitive strategies perform better in reading, incredibly. Finally, the paper puts forward some relevant pedagogical suggestions.
\end{abstract}

\section{Introduction}

With the popularization of higher education in China, the quality of vocational students becomes far from satisfactory, especially their English. Apart from their low motivation to read, unawareness of effective reading strategies is indeed a common problem for them. Hence it counts a lot to the training of the strategies for those vocational college students. By making questionnaires of the freshmen of a vocational college in Shanghai, the paper makes an empirical study of English reading strategies for vocational college students. In an attempt to improve vocational college English teaching in reading comprehension, the study deals with various theories on reading strategies learning and teaching, and puts forward some relevant pedagogical suggestions.

\section{Literature Review}

Literatures for research on English reading comprehension strategies are mainly as follows:

Comprehension strategy instruction became the focus of much research in the 1970s and 1980s. There are various approaches on reading strategies: Story Grammar Instruction and Story Maps, Activating Prior Knowledge and Prediction Method, Word Webs, Multicultural Literature, Cooperative Learning, and the like. First, the story map is used as a visual organization tool which may help to enhance students' memory or recall of the story and learn new vocabulary words [1]. Second, to make good predictions, students should activate and reflect on their prior knowledge of the topic, which are critical to the comprehension process and gives them opportunities to connect their lives with the text [2]. Third, A word web is a type of graphic organizer that has a concept or word in the middle and some attributes with examples around the central concept. The word web can help students make connections between new information and prior knowledge [3]. Fourth, multicultural literature is a strategy that may influence the context of the reader. These contextual factors include attitude and motivation, which can act as mediators to increase reading performance. Multicultural literature refers to narrative stories, folktales, or poetry like themes, images, characters, and dialogue from diverse cultures. educators may use multicultural literature to activate students' background knowledge and increase motivation [4]. Finally, Cooperative learning is another contextual strategy that may enhance reading comprehension by increasing student motivation and engagement and foster an interactive learning environment for students from diverse backgrounds [5]. 
However, It is not until the year 1984 did Chinese researchers begin to study English learning strategies [6]. Since then various literatures on the research have appeared in China, and among them those on vocational college English reading are chiefly the following:

$\mathrm{Bi}$ investigated the case of English reading strategy use in a higher vocational technology college of Shandong Province, finding that the use frequencies of those reading strategies are a bit lower than those of university undergraduates [7]. Chen found, vocational college students, used vocabulary strategies frequently, but seldom used inference strategies [8]. Liu found, vocational college students lack self-confidence, inflexible to use reading skills, with little initiative of independent reading [9].

$\mathrm{Ma}$ and Mo attempted to set up a reading strategies training mode, including pre-reading, in-reading, and post-reading, in higher vocational English classroom teaching [10]. Qiao and Deng thought, reading strategy training teaching improved students' reading fluency, but it had no significant effect on reading accuracy and reading strategy mastering [11].

The above literature review shows, researches on English reading strategies have been rich, yet most of them focus on students in primary schools, middle schools, and universities. Researches concerning vocational college students still seem to be inadequate. Therefore this study hopes to enrich such research, mainly based on the theories by O'Malley and Chamot [12]and Oxford [13].

\section{Theoretical framework}

Based on cognitive theory, O'Malley and Chamot developed a classification of three types of language learning strategies: metacognitive strategies, such as planning for learning, monitoring learning, or evaluating learning; cognitive strategies, such as mental manipulation or transformation of materials or tasks, enhancing comprehension, acquisition, or retention; and social/affective strategies, such as using social interactions to assist in the comprehension, learning or retention of information, as well as the mental control over personal affect that interfered with learning [12].

Oxford developed a taxonomy for categorizing strategies under six headings: cognitive - making associations between new and already known information; mnemonic_-making associations between new and already known information through use of formula, phrase, verse or the like; metacognitive-planning, organization and evaluation of the learning process; compensatory —using context to make up for missing information in reading and writing; affective-regulation of emotions, motivation and attitude toward learning; social—-the interaction with other learners to improve language learning and cultural understanding [13].

Based on the above theories by O'Malley and Chamot, and Oxford, this research conducts a questionnaire, modified from Tsai \& Talley [14], on English reading strategies used by 53 freshmen of mechanical and electrical majors from Shang Publishing and Printing College, including 47 males and 6 females. It attempts to look into an overall use of English reading strategies for vocational college students, and make some pedagogical suggestions concerned.

The questionnaire took place in the October of 2016, including 40 reading strategies in the three categories of meta-cognitive strategies, cognitive strategies, and social-affective strategies. The performance of the students is marked by their score of the reading material in the final test, on an equivalent level of college English test band one, in January of 2017.

\section{Analysis of reading strategy use}

Concepts concerned in data processing are as follows:

ask- asking questions, mon - monitoring, COGNI - cognitive strategies, plan - planning,coopcooperating with others, rea - reasoning, enco - encouraging yourself, retr - Retrieval, lex - lexical inferencing, self - self-evaluation, low - lowering your anxiety, SOCIO - social-affective strategies mem - memory, sum - summarizing, MET -meta-cognitive strategies , tran - transferringsyntactic knowledge 
Table 1 Descriptive Statistics of reading strategies

\begin{tabular}{|l|l|l|l|l|}
\hline & Minimum & Maximum & Mean & Std. Deviation \\
\hline MET & 1.62 & 4.38 & 3.026 & 0.664 \\
\hline COGNI & 1.77 & 4.32 & 2.976 & 0.640 \\
\hline SOCIO & 1.6 & 4.6 & 2.868 & 0.724 \\
\hline score & 15 & 72 & 48.803 & 13.404 \\
\hline
\end{tabular}

Table 1 shows the overall performance of the students in reading is rather poor, with a mean of 48.803 and the standard deviation of more than 13. It also shows they use the reading strategies not so often, among the three strategies, the meta-cognitive strategies use is most frequent, with a mean of 3.026, and the social-affective strategies use is least frequent, with a mean of 2.868 .

Table 2 Descriptive Statistics of reading sub-strategies

\begin{tabular}{|c|c|c|c|c|c|c|c|c|c|c|c|}
\hline MET & Mean & MET & Mean & COGNI & Mean & COGNI & Mean & COGNI & Mean & SOCIO & Mean \\
\hline mon5 & 2.547 & mon3 & 3.132 & retr5 & 2.377 & tran2 & 2.887 & lex6 & 3.189 & ask & 2.604 \\
\hline self4 & 2.755 & self1 & 3.151 & lex1 & 2.472 & tran4 & 2.943 & lex3 & 3.226 & coop2 & 2.642 \\
\hline self2 & 2.811 & rea1 & 3.170 & retr4 & 2.472 & mem1 & 3.000 & mem2 & 3.245 & coop1 & 2.811 \\
\hline rea3 & 2.830 & mon4 & 3.302 & lex5 & 2.623 & mem4 & 3.057 & mem3 & 3.302 & low & 2.925 \\
\hline self3 & 2.887 & mon2 & 3.321 & sum2 & 2.660 & retr3 & 3.076 & tran3 & 3.359 & enco & 3.359 \\
\hline plan & 2.906 & mon1 & 3.415 & retr2 & 2.736 & sum1 & 3.094 & mem5 & 3.415 & & \\
\hline rea2 & 3.113 & & & tran1 & 2.830 & lex2 & 3.132 & lex4 & 3.509 & & \\
\hline & & & & retr1 & 2.868 & & & & & & \\
\hline
\end{tabular}

Table 2 displays the detailed uses of each sub-strategy of the three reading strategies. First, mong the 13 meta-cognitive sub-strategies, mon1(I try to get back on track when I lose concentration), mon2 (I underline or circle information in the text to help me remember it), and mon4(I scan key words, phrases, ideas, linguistic markers, or types of information) are most frequently used; while self2 ( I stop from time to time and think about what I'm reading), self4 ( I know which strategy to use and how and when to use it), and mon5 (I identify structural or meaning errors) are least frequently used. This suggests the students can monitor their reading quite often by scanning and marking the key words, but they often fail to evaluate their own reading strategies and identify the errors in the reading material. Second, among the 22 cognitive sub-strategies, the 3 most frequently used are lex 4 (I try to understand the texts and questions regardless of my vocabulary knowledge), mem5 (I repeat the portion of the text, including the word, phrase, or sentence that I don't understand), and tran3 (I translate words or sentences in Chinese ); while the 3 least frequently used are retr4 ( I use tables, figures, and pictures in text to increase my understanding ), lex1 ( I analyze words into various components, such as roots, affixes, and suffixes ), and retr5 ( I use typographical aids like boldface and italics to identify key information ). This suggests, on the one hand, the students tend to comprehend by making blind inferences, rereading, and even translating the material into their mother tongue Chinese; on the other hand, they often fail to retrieve the meaning of the reading material with some visual aids such as tables, figures, pictures, typefaces of the words, and word-forms. This may be due to their being majors of technology, unaccustomed to the concrete thinking. Finally, among the 5 social-affective sub-strategies, the most frequently used is enco ( I think positively and believe in myself that I can solve the reading problem ) and low ( I reduce anxiety by improving the sense of competence ); while the least frequently used is coop2 ( I work with peers to complete a task, pool information, solve a problem, or get feedback ), and ask ( I ask a teacher or other experts in order to understand the material ). It can be seen that the students can often encourage themselves and lower their anxiety to solve the reading problem on the one hand; yet they fail to ask the teacher or other peer students for help on the other hand. 
Table 3 Correlations between sex, score, and reading strategies

\begin{tabular}{|l|l|l|l|l|l|}
\hline & score & MET & COGNI & SOCIO & sex \\
\hline score & 1 & -0.122 & $-.354^{* *}$ & -0.067 & $.474^{* *}$ \\
\hline MET & -0.122 & 1 & $.647^{* *}$ & $.731^{* *}$ & $-.410^{* *}$ \\
\hline COGNI & $-.354^{* *}$ & $.647^{* *}$ & 1 & $.746^{* *}$ & $-.509^{* *}$ \\
\hline SOCIO & -0.067 & $.731^{* *}$ & $.746^{* *}$ & 1 & $-.414^{* *}$ \\
\hline sex & $.474^{* *}$ & $-.410^{* *}$ & $-.509^{* *}$ & $-.414^{* *}$ & 1 \\
\hline
\end{tabular}

Notes: *p $<0.05 ; * * \mathrm{p}<0.01$.

From table 3, it can be seen that, first, interestingly and unusually, the performance of male students is better than that of females $(\mathrm{t}=0.474, \mathrm{p}<0.01)$, and the reason may partly be that only $11.3 \%$ of the students are females while 88.7 of them are males. Second, the female students use the three categories of reading strategies more frequently than their counterpart males. Thirdly among the 3 reading strategies, only the cognitive strategy is negatively correlated with score $(\mathrm{t}=-0.354, \mathrm{p}<$ 0.01), suggesting that those less frequently using cognitive strategies perform better in reading, incredibly. Finally, there are positive correlations between the three categories of reading strategies: MET/ COGNI ( $\mathrm{t}=0.647, \mathrm{p}<0.01)$, MET/ SOCIO $(\mathrm{t}=0.731, \mathrm{p}<0.01)$, and COGNI/ SOCIO $(\mathrm{t}=0$. $746, \mathrm{p}<0.01$ ), indicating that those often using the meta-cognitive strategies will frequently use the cognitive strategies and the social-affective strategies as well.

Table 4 Correlations between sex, score, and reading sub-strategies

\begin{tabular}{|c|c|c|c|c|c|c|c|c|c|}
\hline & lex1 & mem5 & mon3 & & & & & \\
\hline e scor & $.274^{*}$ & $.298^{*}$ & $.320^{*}$ & & & & & \\
\hline & $\operatorname{tran} 3$ & coop2 & rea2 & mon2 & enco & lex1 & lex3 & mon3 & lex5 \\
\hline sex & $-.276^{*}$ & $-.279^{*}$ & $-.293^{*}$ & $-.299^{*}$ & $-.316^{*}$ & $-.341^{*}$ & $-.341^{*}$ & $-.342^{*}$ & $* .344$ \\
\hline & $\operatorname{mem} 1$ & lex6 & plan & tran2 & mon5 & mem2 & sum1 & retr5 & \\
\hline sex & $-.358^{*}$ & $-.368^{*}$ & $-.379^{*}$ & $-.384^{*}$ & $-.415^{*}$ & $-.419^{*}$ & $-.435^{*}$ & $-.446^{*}$ & \\
\hline
\end{tabular}

Notes: *p $<0.05 ; * * \mathrm{p}<0.01$.

Table 4 describes the correlations between the sub-strategies and score, and sex. For one thing, despite that the overall cognitive strategy is negatively correlated with score, there are still two cognitive sub-strategies and one meta-cognitive sub-strategy are positively correlated with score: lex1/ score $(\mathrm{t}=0.274, \mathrm{p}<0.05)$, mem5/ score $(\mathrm{t}=0.298, \mathrm{p}<0.05)$, and mon3/ score $(\mathrm{t}=0.320, \mathrm{p}<$ 0.05). This means that those who can use memory strategy by note-taking, make lexical inference by word-formation, and use monitoring strategy by persisting in completing the reading task on time, can get better performance in reading.

For another, the female students prefer to use the following 17 sub-strategies in reading: tran3, coop2, rea2, mon2, enco, lex1, lex3, mon3, lex5, mem1, lex6, plan, tran2, mon5, mem2, sum1, and retr5. That is, females best like to use the retrieval strategy by with some typographical aids like boldface and italics to identify key information, use the summarizing strategy, by paraphrasing to better understand what they read, and use memory strategy via context clues to better understand the meaning. Relatively speaking, females less like to use reasoning strategy to guess the meaning of the material, cooperate with others to complete a reading task, and translate words or sentences in Chinese.

\section{Conclusion}

Based on the above analyses, some pedagogical suggestions are raised as follows:

First, in the light of the overall poor performance, the students should be taught to accumulate sufficient basic English language knowledge.

Second, to solve their reading problems, the students should learn adequate reading strategies, such as planning(setting goals for reading), retrieval(identifying key words or key information with typographical aids like boldface and italics, or tables, figures, and pictures in text), summarizing 
(making a mental, oral, or written summary of information gained from reading), asking teachers questions, cooperating with others to solve a problem, monitoring (identify structural or meaning errors), self-evaluation, reasoning (identifying the organizing principle of the reading material), lexical inference (word-formation, classifying words), and so on.

Finally, the students are encouraged to make full use of their own talent in classrooms to enhance their motivation to read. For instance, students with high musical gift may volunteer to sing or listen to music, while those strong at bodily intelligence may offer to make role-plays.

\section{References}

[1] V. M.Naughton, “Picture it! ”, Reading Teacher, 2008. 62(1) , pp. 65-68.

[2] P. A. Alexander, T. L. Jetton, "Learning from text: A multidimensional and developmental perspective”, M. L. Kamil, P. B. Mosenthal, P. D. Pearson, \& R. Barr (Eds.), Handbook of reading research: 2000. Vol. III (pp. 285-310). Mahwah, NJ: Erlbaum. Almaguer, I.

[3] D.Miller, "Reading with meaning: Teaching comprehension in the primary grades. Portland”, ME: Stenhouse Publishers, 2002.

[4] M. McCollin, D. O’Shea, "Increasing reading achievement of students from culturally and linguistically diverse backgrounds”, Preventing School Failure, 2005. 50(1), pp. 41-44.

[5] W. Montgomery, “Creating culturally responsive, inclusive classrooms”, Teaching Exceptional Children, 2001. 33(4), pp. 4-9.

[6] Y. Huang, A study on the effectiveness of English reading strategies training for non-English majors in a vocational college, Fujian Normal University, MA Thesis, 2015.

[7] M. X. Bi, A tentative study on reading strategies of higher vocational technology college students, Shandong University, MA Thesis, 2007.

[8] P. Chen, A study of English reading strategies for vocational college students, Central China Normal University, MA Thesis, 2014.

[9] F. Liu, "Investigation and analysis of the English reading situation of higher vocational students", Journal of Jiujiang Vocational and Technical College, 2015. 4, pp.39-41.

[10]Y. L. Ma, G. H. Mo, “A tentative study of reading strategies training mode in higher vocational English classroom teaching”, Journal of Harbin Vocational \& Technical College, 2010.6, pp. : 30-31.

[11]Y. Qiao, L. Deng, “An empirical study of English reading teaching based on strategy training in vocation college”, Foreign Language Education in China, 2014. 3, pp. 32-38.

[12] J. C. O'Malley, A Learning Strategies in Second Language Acquisition. Cambridge: Cambridge University Press, 1990.

[13]R. Oxford, Language Learning Strategies: What Every Teacher Should Know. NY: Newbury House Publisher, 1990.

[14]Y. R. Tsai \& P. C. Talley, "The effect of a course management system (CMS)-supported strategy instruction on EFL reading comprehension and strategy use”, Computer Assisted Language Learning, 2014. 27:5, pp.422-438. 